\title{
Leukemic Blast Count
}

National Cancer Institute

\section{Source}

National Cancer Institute. Leukemic Blast Count. NCI Thesaurus. Code C74630.

The determination of the number of leukemic blasts present in a sample. 